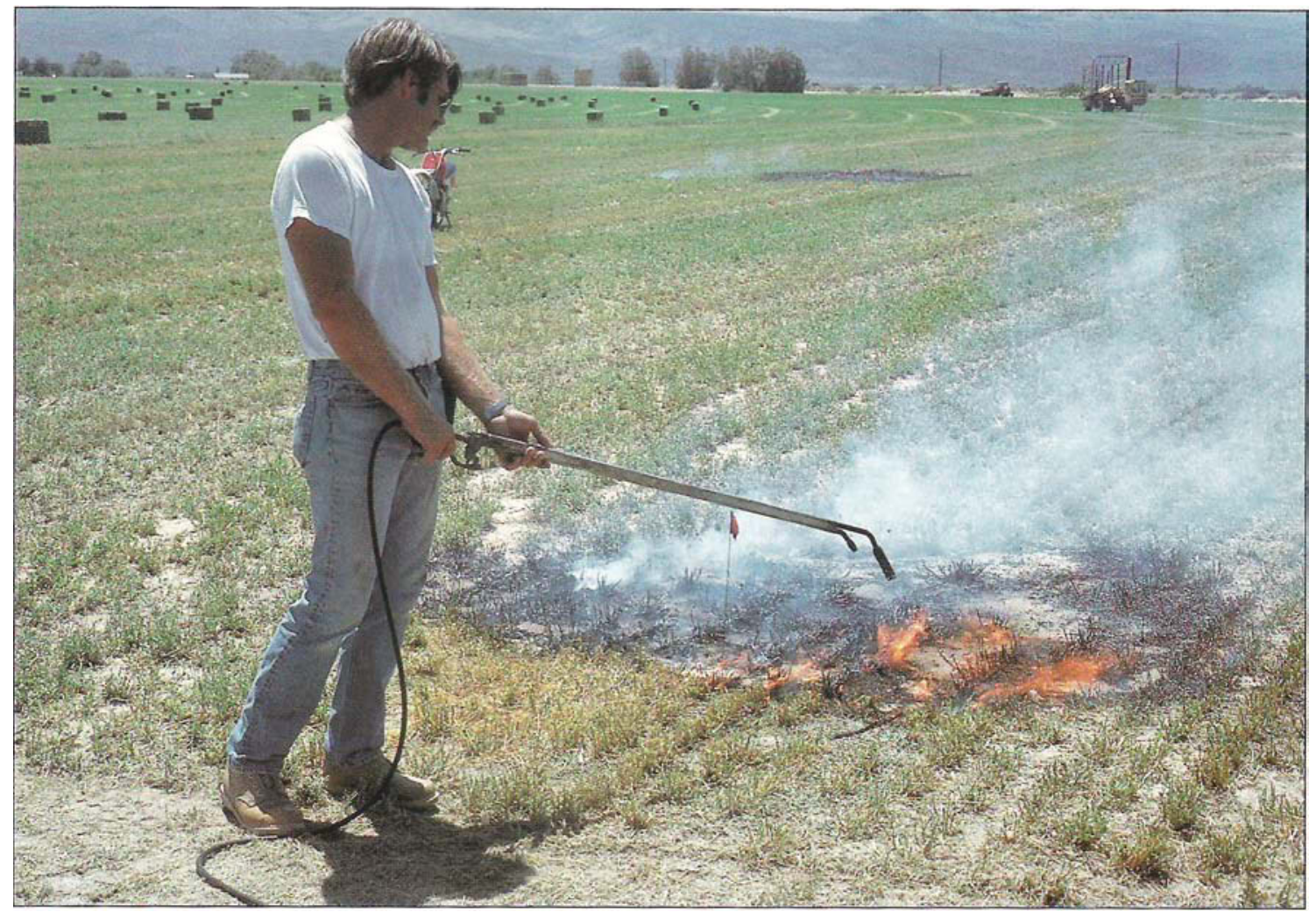

\title{
Controlling dodder in alfalfa hay calls for an integrated procedure
}

\section{Steve B. Orloff $\square \quad$ David W. Cudney}

\begin{abstract}
Dodder is a troublesome parasitic weed in alfalfa hay fields. Preemergence treatment with trifluralin controls dodder early in the season, but as the season progresses, control declines. Flail mowing escaped dodder patches in midseason followed by burning in late season, when dodder seed was being produced, was found to be an effective, integrated control procedure.
\end{abstract}

Dodder (Cuscuta sp.) is an annual parasitic weed in alfalfa hay (Medicago sativa L.). This rootless plant attaches itself to the host soon after germination. Upon attachment, dodder survives at the expense of the host plant. It develops rapidly after attachment, growing as much as $8 \mathrm{~cm}$ ( 3.15 inches) per day. Although a parasite does not generally kill its host, dodder weakens the alfalfa plant to such a degree that eventually, if left uncontrolled, it will kill some plants, weaken the alfalfa stand and reduce forage yields. Dodder also reduces hay quality. Because of the succulent nature of dodder, dodder-infested hay may require at least one extra day to cure or dry before baling.

Large-seeded dodder (C. indecora Choisy) has interfered with the production of alfalfa hay in Southern California's high desert region, where as much as $90 \%$ of the alfalfa fields are reportedly infested with it. Most of the dodder emerges and attaches to its host between March and May, but it continues to germinate and attach at a reduced rate until October. When left uncontrolled, the dodder plant can form a dense, orange mat greater than $3 \mathrm{~m}(10 \mathrm{ft})$ in diameter. These mats can coalesce late in the season, forming even larger mats, stretching clear across fields.

Dodder begins flowering in July in the high desert and continues its reproductive phase into October. Most dodder seed development occurs in September and October. Dodder seed can remain viable in the soil for 10 years or more.
The most common dodder control method in the high desert before 1986 was spot treatment with dinoseb herbicide (no longer permitted in the United States). This practice was of limited value, as it was difficult to find and treat all of the affected areas. Dodder continued to emerge throughout the growing season, necessitating spot treatment after each cutting. The introduction in 1986 of trifluralin granules for pre-emergence control of dodder significantly improved control. In studies conducted throughout California, the average dodder control with trifluralin was 96,88 and $72 \%$ for early season, midseason and late-season evaluations, respectively.

Because complete control is not achieved and dodder seed production occurs primarily late in the growing season, a method for controlling dodder plants that escape pre-emergence treatment is needed. Therefore, additional methods of spot treatment should be evaluated. Two cultural methods are feasible: burning dodder-infested alfalfa plants with a propane-fueled burner or close mowing infested alfalfa plants. For 


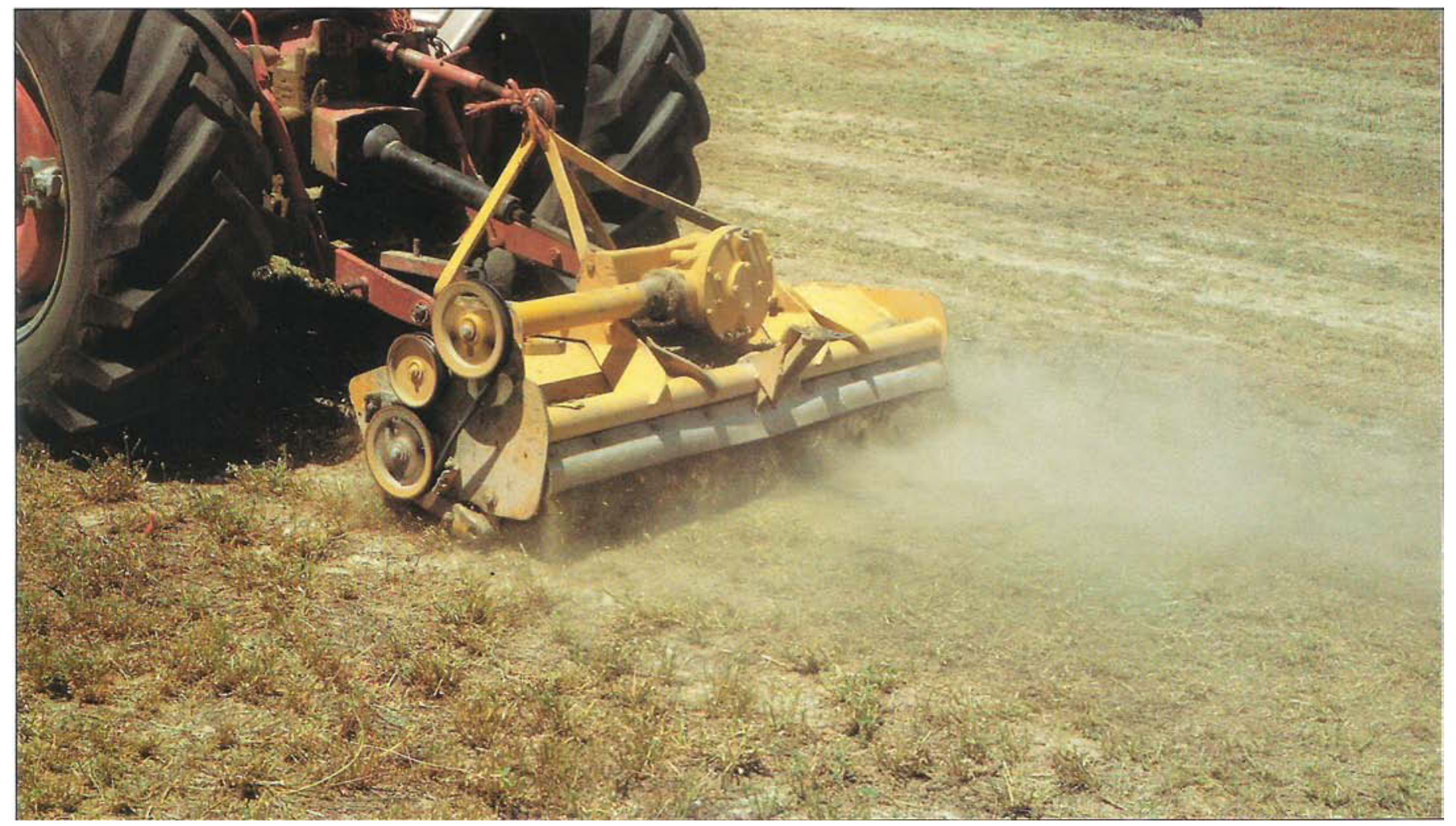

At left, spot burning of attached dodder with a propane-fueled weed burner, demonstrated by Steve Orloff, Siskiyou County farm advisor.
Above, Flail mowing of attached dodder is an attractive alternative to burning, as it is less costly, less damaging to alfalfa and easier for the operator to manage. either method to be effective, the alfalfa host must be destroyed below the point of dodder attachment. This damages the alfalfa plant, but the dodder poses a much more serious problem.

A component of successful long-term dodder control is to limit or halt the production and distribution of viable dodder seed to the soil. The traditional approach has been to control dodder patches before seed-set occurs. Often this is not achieved, as some dodder plants are not detected before seed-set. Burning may be an effective means of destroying dodder seed.

Our research sought to: (1) compare the effectiveness of close mowing and burning to control attached dodder, (2) determine the impact of these practices on alfalfa plants and (3) assess the costs of these practices.

\section{Trials in infested fields}

\section{Mowing and burning compared.}

Two field experiments were conducted, in 1988 and 1991, in 3-year-old alfalfa fields heavily infested with dodder. Both trials were conducted near Dagett, in
Southern California's Mojave desert. The plots were 2 by $6 \mathrm{~m}(6.6$ by $20 \mathrm{ft})$ in size. The experiment was arranged in a completely randomized design with two-way factorial treatments and five replications. The first factor was dodder-infested alfalfa versus uninfested alfalfa. The second factor was dodder control method: burning, flail mowing or no treatment.

The plots were established in August, 5 days after the fourth alfalfa harvest, in vigorously growing alfalfa that was both uninfested and newly infested with dodder. Close mowing was accomplished with a flail mower, adjusted so that the alfalfa was severed at the soil surface. Alfalfa was burned with a hand-held, propane-fueled, wand-type weed burner. Soil surface temperatures reached $650^{\circ} \mathrm{C}$ $\left(1200^{\circ} \mathrm{F}\right)$. All aboveground portions of the alfalfa were charred.

At the fifth harvest, a 1- by 5-m (3.3by $16-\mathrm{ft}$ ) swath was harvested from each plot to determine total dry matter. Alfalfa plant density was determined after harvest by counting the number of surviving alfalfa plants per square meter. Data were subjected to an analysis of variance, and means were separated using Fisher's protected least significant difference (LSD) at $P=0.05$. There was no significant year by treatment interaction; therefore, data were averaged over both years.

Cost of control practices. An economic evaluation of flail mowing and burning was made by using farm costs of these operations. The farm costs consisted of expenditures for labor $(\$ 6.10$ per hour) and materials: tractor fuel, equipment maintenance, taxes, interest, insurance and equipment purchase. Equipment purchase cost was depreciated over 20 years, assuming a 150-hectare (370-acre) alfalfa farm with 50 dodder patches per hectare.

Dodder seed survival. Three field experiments were conducted to determine the effect of burning on dodder seed viability. Experiments were conducted in commercial alfalfa fields in the Lucerne Valley during 1986 and east of Lancaster during 1987 and 1989. Each trial was initiated in September (after the fifth alfalfa harvest) in areas highly infested with dodder which had mature seed. 

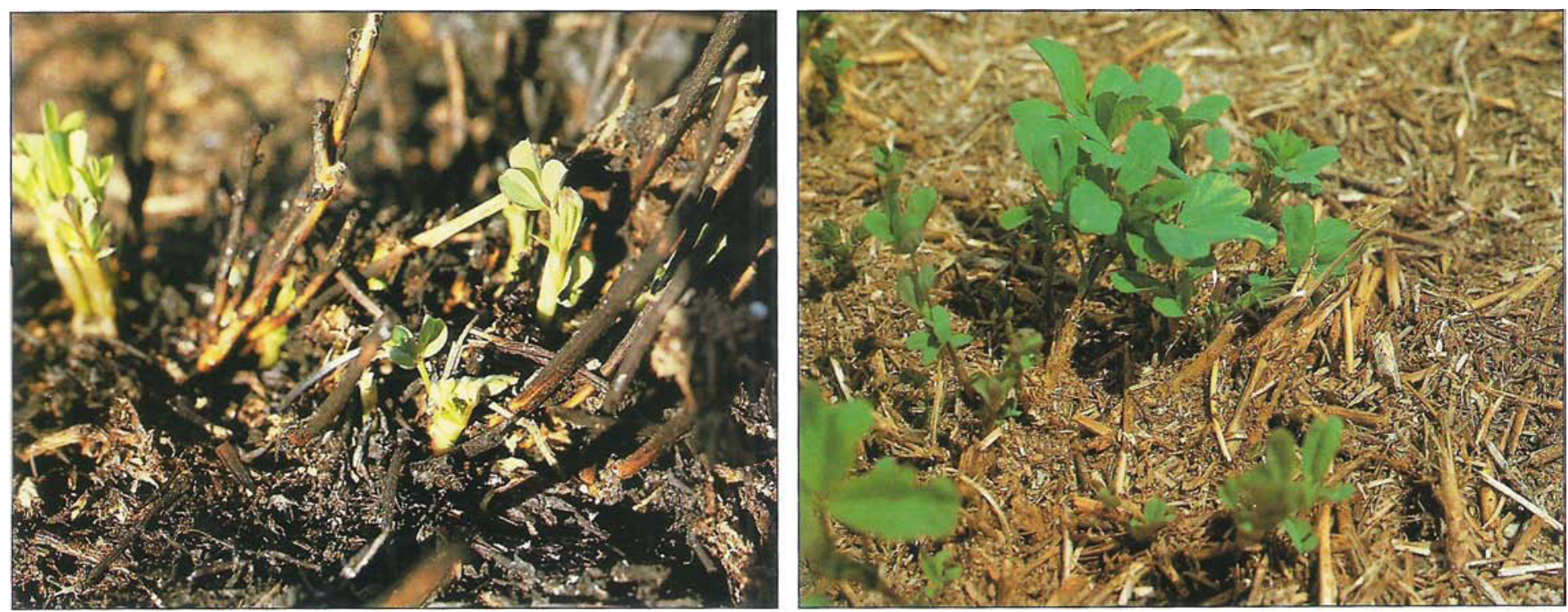

Burned and mowed plants 1 week after treatment. Note that the mowed plants have significantly more regrowth.
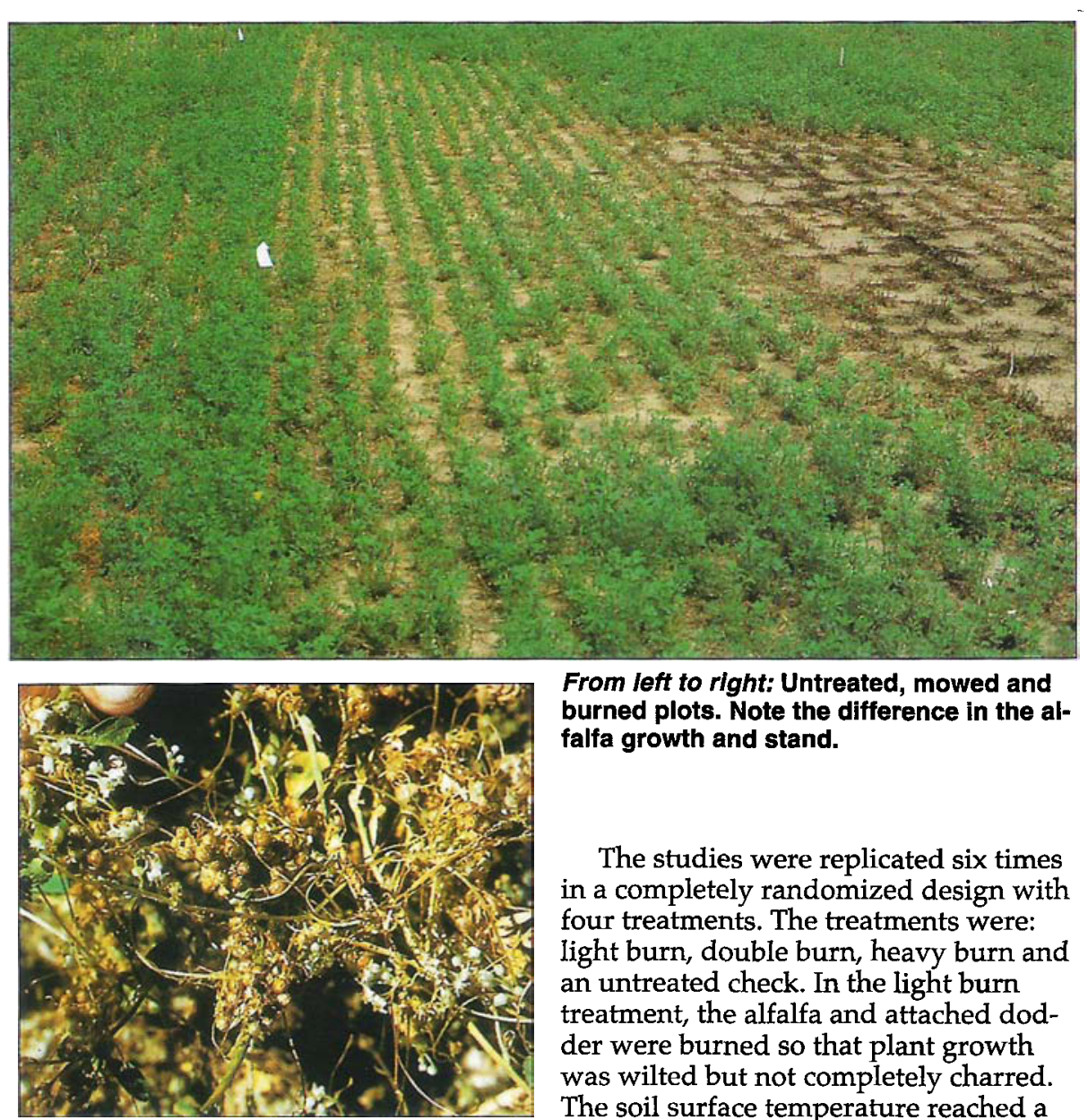

Dodder is a prolific seed producer with three or four seeds in each capsule. Burning at the end of the season was found to reduce dodder seed viability by more than $99 \%$.
From left to right: Untreated, mowed and burned plots. Note the difference in the alfalfa growth and stand.

The studies were replicated six times in a completely randomized design with four treatments. The treatments were: light burn, double burn, heavy burn and an untreated check. In the light burn treatment, the alfalfa and attached dodder were burned so that plant growth was wilted but not completely charred. The soil surface temperature reached a maximum of $340^{\circ} \mathrm{C}\left(644^{\circ} \mathrm{F}\right)$. The double burn consisted of two light burn treatments spaced 2 days apart. The heavy burn was accomplished in a similar fashion as the light burn, except that the soil surface temperature reached $650^{\circ} \mathrm{C}$ $\left(1200^{\circ} \mathrm{F}\right)$ and plant growth was completely charred. These three treatments were done to simulate the grower practices that were normal in the area, the heavy burn being the most common.

Plot size was 1 by $2 \mathrm{~m}$ ( 3.3 by $6.6 \mathrm{ft})$. An iron frame $\left(0.2 \mathrm{~m}^{2}\right.$ or $\left.2 \mathrm{ft}^{2}\right)$ enclosed with a wire mesh was used during the burning and sampling of the plots. This was to ensure that all of the dodder seed remained in the area to be sampled and was not blown out during the flaming operation. After all treatments were completed, the plant debris and $1 \mathrm{~cm}$ of soil ( 0.39 inches) were removed from the $0.2 \mathrm{~m}^{2}$ sample area and taken to a greenhouse at UC Riverside to determine dodder seed viability. Soil and plant debris from each sample area were then placed on the surface of two $0.25 \mathrm{~m}^{2}$ flats containing a planting mix composed of $25 \%$ peat, $25 \%$ vermiculite and $50 \%$ sand. The flats were irrigated daily to ensure adequate moisture for germination. Greenhouse temperatures fluctuated from daytime maximums of $29^{\circ} \mathrm{C}$ $\left(84^{\circ} \mathrm{F}\right)$ to nighttime minimums of $18^{\circ} \mathrm{C}$ $\left(64^{\circ} \mathrm{F}\right)$. Emergence of dodder seedlings was logged daily for 4 weeks. The soil was allowed to dry for 4 days, the surface of the flats was mixed, irrigation was re-initiated and dodder seedling emergence was monitored for an additional 10 days. Emergence data were summed for each pair of flats, then subjected to an analysis of variance; means were separated by Fisher's protected LSD at $P=0.05$. There was no year-bytreatment interaction. Therefore, data were combined over the 3 years. 


\begin{tabular}{|c|c|c|c|c|c|c|c|}
\hline \multirow[b]{2}{*}{ Method } & \multicolumn{5}{|c|}{ Cost } & \multirow{2}{*}{$\begin{array}{l}\text { Hours } \\
\text { required/ha }\end{array}$} & \multirow{2}{*}{$\begin{array}{l}\text { Total } \\
\text { S/ha }\end{array}$} \\
\hline & Labor & Tractor $^{\star}$ & Equipment† & Fuel‡ & Total & & \\
\hline & \multicolumn{7}{|c|}{ 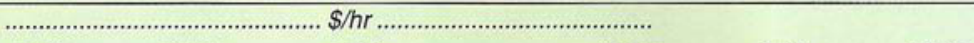 } \\
\hline Flail mowing & 6.10 & 10.39 & 2.78 & - & 19.27 & 0.69 & 13.30 \\
\hline Burning & 6.10 & 8.16 & 2.43 & 14.40 & 31.09 & 1.50 & 46.64 \\
\hline
\end{tabular}

\section{Results}

Mowing and burning comparison. The presence of dodder significantly affected total dry matter (fig. 1). Dry matter yield was reduced by $42 \%$ when the dodder was untreated. When dodder was absent, burning alone reduced yield to $2,090 \mathrm{~kg} / \mathrm{ha}(1,867 \mathrm{lb} / \mathrm{ac})$ compared with that of the untreated check $(2,940$ $\mathrm{kg} /$ ha or $2,621 \mathrm{lb} / \mathrm{ac}$ ). Dry matter was not reduced as much by flail mowing $(2,560 \mathrm{~kg} / \mathrm{ha}$ or $2,282 \mathrm{lb} / \mathrm{ac})$. A significant interaction was found between treatment and dodder presence. When dodder was present, the highest yield was obtained in the mowed plots $(2,240$ $\mathrm{kg} / \mathrm{ha}$ or $1,997 \mathrm{lb} / \mathrm{ac}$ ) compared with the burned or untreated plots $(1,370$ and $1,700 \mathrm{~kg} / \mathrm{ha}$, or 1,221 and 1,516 lb/ ac, respectively).

Similar results were observed for alfalfa density (fig. 2). The presence of dodder reduced alfalfa stand density from 48 to 31 plants $/ \mathrm{m}^{2}$ ( 48 to 31 plants / $3.3 \mathrm{ft}^{2}$ ) when averaged across all treatments. Mowed plots maintained the highest alfalfa density when dodder was present compared with burned and untreated plots (41 compared with 25 and 26 plants $/ \mathrm{m}^{2}$, respectively). When dodder was absent, untreated plots maintained the highest alfalfa density followed by mowed and burned plots (57 compared with 49 and 38 plants $/ \mathrm{m}^{2}$ ).

Cost of mowing versus burning. The hourly equipment costs were similar for both methods of control (table 1). Tractor costs for mowing were slightly higher due to higher power requirements of mowing compared to burning. However, the greatest difference in cost was the $\$ 14.40$ fuel cost for burning. Total hourly costs for mowing were $\$ 19.27$ and $\$ 31.09$ for burning. Mowing required approximately half the time of burning (0.69 and $1.5 \mathrm{hr} / \mathrm{ha}$, or 0.28 and $0.61 \mathrm{hr} / \mathrm{ac}$, respectively). Therefore, mowing when figured on a hectare rather than hourly basis was less than one-third the cost of burning.
Dodder seed survival. The effects of burning were similar for each of the 3 years. All three burning treatments significantly lowered dodder emergence compared with the untreated check (fig. 3). Burning reduced dodder emergence by an average of $99 \%$. When comparisons were made among burn treatments, double- or heavy-burn treatments resulted in significantly less dodder emergence than single-burn treatments.

\section{Conclusions}

The results of this research can be integrated into a complete dodder management program in alfalfa hay fields. Pre-emergence trifluralin treatment controls approximately $96 \%$ of emerging dodder early in the season. However, with time, control declines to less than $80 \%$. Thus, postattachment control methods, such as mowing and burning, become increasingly important as the season progresses. In midseason, when surviving dodder plants are observed, they should be controlled by flail mowing. In the tests, flail mowing was less detrimental to alfalfa than burning. Mowing was also more economical and faster. However, for flail mowing to be effective, fields must be relatively level or the alfalfa will not be mowed below the point of dodder attachment in the low areas and the dodder will survive. Also, flail mowing can be difficult along the borders of flood-irrigated alfalfa fields unless the borders are shaped so that the flail mower can be operated perpendicular to the borders.

Late in the season, when dodder seed is maturing, burning becomes the preferred control. Traditionally, growers have not been concerned with late-season dodder control because dodder is not actively growing then and alfalfa harvesting has ceased. However, control at this time is critical to prevent seed production and destroy existing dodder seed.

The combination of all three control strategies, pre-emergence treatment, flail mowing and burning, results in

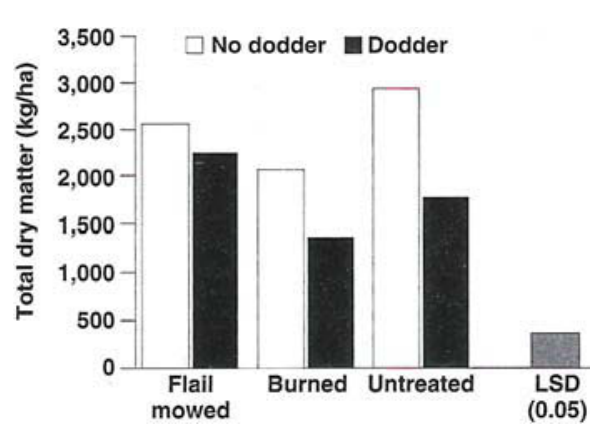

Fig. 1. Effects of mowing and burning alfalfa with and without attached dodder on total dry matter production at the following harvest (an average of data from two experiments, 1989 and 1991).

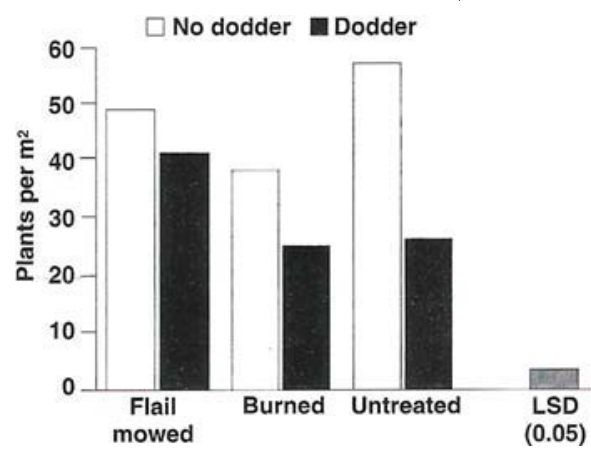

Fig. 2. Effects of mowing and burning alfalfa with and without attached dodder on alfalfa stand density at the following harvest (an average of data from two experiments, 1989 and 1991).

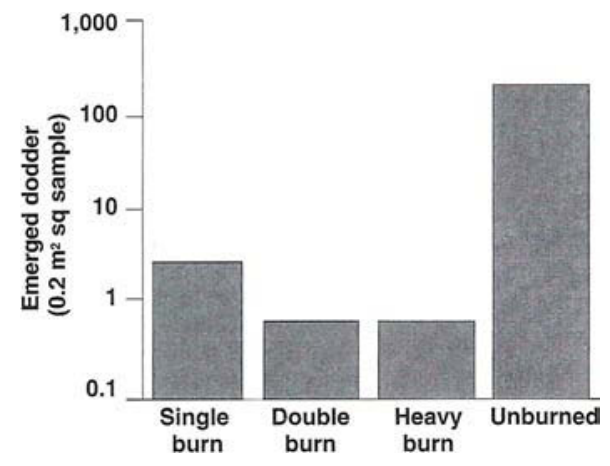

Fig. 3. Dodder which emerged in greenhouse flats from $1 \mathrm{~cm}$ of soil and plant debris collected from $0.2 \mathrm{~m}^{2}$ sample sites in burned and unburned plots.

lower dodder emergence, minimizes detrimental effects to the alfalfa and reduces the return of viable dodder seed to the soil.

S. B. Orloff is Farm Advisor, Siskiyou County, and D. W. Cudney is Extension Weed Scientist, UC Riverside. 